\begin{tabular}{|c|c|c|}
\hline st & $\begin{array}{l}\text { CARADDE: Jurnal Pengabdian Kepada Masyarakat } \\
\text { https://journal.ilininstitute.com/index.php/caradde } \\
\text { Volume } 2 \text { | Nomor } 1 \text { | Agustus | 2019 } \\
\text { e-ISSN: } 2621-7910 \text { dan p-ISSN: } 2621-7961 \\
\text { DOI: https://doi.org/10.31960/caradde.v2i1.103 }\end{array}$ & $\begin{array}{l}\text { IUIN } \\
\text { GaBADDE }\end{array}$ \\
\hline
\end{tabular}

\title{
Program Green Campus melalui Penanaman Pohon Ketapang Kencana (Termenelia mantily) dan Ki Hujan (Samanea saman) dalam Upaya Mengurangi Global Warming
}

\author{
Makmur $^{1}$, Ikawati Karim ${ }^{2}$
}

\author{
Keywords : \\ Green Campus; \\ Ketapang Kencana; \\ Ki Hujan; \\ Global Warming.
}

\section{Corespondensi Author}

Agribisnis, Universitas Sulawesi

Barat J1.Prof.Dr.Baharuddin Lopa, SH, Talumung, Mejene 91412

Email: ikawati@unsulbar.ac.id

\author{
History Artikel \\ Received: Januari-2019; \\ Reviewed: April-2019 \\ Reviewed: April-2019 \\ Accepted: April-2019 \\ Published: Juni-2019
}

\begin{abstract}
Abstrak. Green campus sebagai wujud kecintaan terhadap lingkungan yang perlu ditumbuhkan akan di mulai dari lingkungan internal kampus melalui gerakan penanaman 100 pohon yang terdiri dari pohon ketapang kencana (Termenelia mantily) dan ki hujan (Samanea saman) disekitar areal kampus dengan melibatkan mahasiswa Fakultas Pertanian dan Kehutanan. Gerakan penanaman 100 pohon ini diharapkan mampu membawa lingkungan kampus di Universitas Sulawesi Barat sebagai kampus yang hijau, asri dan nyaman. Program penanaman 100 pohon diharapkan menjadi langkah awal timbulnya kesadaran untuk menjadikan Universitas Sulawesi Barat sebagai ecogreen campus. Salah satu elemen dari penerapan eco-green campus adalah green open space melalui gerakan menghijaukan ruang terbuka di areal sekitar bangunan baik perkantoran dan ruang perkuliahan di kampus PadangPadang, rektorat dan LPPM Universitas Sulawesi Barat. Selain green open space ke depannya, elemen green campus yang lain seperti green movement, green transportation dan green energy dapat diterapkan di Unversitas Sulawesi Barat seperti yang telah diterapkan oleh kampus-kampus besar di Indonesia seperti Institut Pertanian Bogor (IPB). Program ini selain tujuan utama yang ingin dicapai dalam mewujudkan green campus di Universitas Sulawesi Barat juga membantu program dunia dalam mengurangi pemanasan global (global warming).
\end{abstract}

\section{PENDAHULUAN}

Universitas Sulawesi Barat merupakan kampus yang didirikan sejak tahun 2013, kampus baru yang tentunya membawa harapan besar dapat membawa perubahan yang baik bagi masyarakat dan lingkungan sekitar. Bukan hanya pengembangan sumber daya manusia yang handal tetapi salah satu peran penting lainnya adalah peran serta dalam aktivitas penyelematan lingkungan. Melihat areal dan public space di sekitar kampus yang masih jauh dari kata "hijau" sehingga menimbulkan kesadaran untuk menginisiasi program green campus yang dimulai dari kegiatan penghijauan melalui penanaman 100 pohon yang terdiri dari 2 (dua) jenis tanaman yaitu Ketapang Kencana (Termenlia mantily) dan $\mathrm{Ki}$ 
Hujan (Samanea saman). Area di sekitar lingkungan di sekitar kampus, baik lokasi perkantoran maupun bangunan perkuliahan masih terbilang gersang, ditambah iklim di Majene termasuk iklim panas. Oleh karena itu, kegiatan penghijauan kampus sangat penting untuk dilakukan, mengingat kampus merupakan tempat belajar sehingga perlu menciptakan lingkungan senyaman mungkin. Green campus harus dimulai dengan hal-hal yang sederhana tapi memberikan dampak yang baik bagi lingkungan. Saat ini pohon yang tumbuh di wilayah sekitaran kampus masih sangat sedikit jumlahnya sehingga kegiatan penghijauan kampus melalui penanaman pohon dianggap penting untuk dilakukan. Selain itu, perlu mengajak mahasiswa sebagai wujud nyata untuk mencintai lingkungannya.

Mengingat pentingnya tanaman atau tumbuh-tumbuhan hijau bagi kelangsungan hidup manusia dan ekosistem untuk melangsungkan kehidupannya di mana tumbuh-tumbuhan hijau menerima sinar matahari, air $\left(\mathrm{H}_{2} \mathrm{O}\right)$, dan karbon dioksida $\left(\mathrm{CO}_{2}\right)$, dari lingkungan sekitarnya yang kemudian diubah menjadi oksigen $\left(\mathrm{O}_{2}\right)$ dan karbohidrat $\left(\mathrm{C}_{6} \mathrm{H}_{12} \mathrm{O}_{6}\right)$. Dengan berkurangnya tanaman hijau, maka lingkungan kampus terasa panas dan tidak nyaman (Alfianto, 2015). Tumbuhan hijau menjadi solusi berbagai problem iklim yang mendera bumi saat ini, seperti isu pemanasan global (global warming) akibat emisi karbondioksida yang melebihi batas oleh adanya efek rumah kaca (Nugraha \& Adrian, 2015).

Olehnya itu, lebih jauh tentang green campus telah diinisiasi oleh beberapa kampus besar di Indonesia telah menerapkan metode ini, salah satunya adalah Institut Pertanian Bogor (IPB) dengan komitmen akan mengurangi emisi karbon Indonesia dengan target $15 \%$. Beberapa langkah taktis yang ditempuh IPB menuju IPB ECO/GREEN campus 2020 melalui 4 (empat) elemen yaitu, (1) green movement, (2) green transportation, (3) green energy dan (4) green building/open space (Boer, 2014). Mengawali wujud untuk menjadikan Universitas Sulawesi Barat menjadi green campus dimulai dari penanaman pohon di ruang-ruang terbuka di sekitar lingkungan kampus atau dengan kata lain green open space, menjadikan lingkungan kampus hijau dan nyaman bagi setiap unsur yang berada di dalamnya, baik mahasiswa, dosen maupun pegawai. Dengan begitu, akan tercipta suasana yang nyaman untuk belajar dan lingkungan yang asri serta dampak positif keberadaan kampus Universitas Sulawesi Barat yaitu mendukung Majene sebagai salah satu Kabupaten yang terbilang tropis di Sulawesi Barat untuk lebih hijau dan sejuk.

Melalui green open space oleh IPB ditempuh dalam 3 (tiga) aksi yaitu (1) membatasi penggunaan Air Conditioning (AC) melalui peningkatan sistem sirkulasi udara di semua gedung/bangunan, (2) menghijaukan area parkir untuk memberi kenyamanan dan keindahan kampus, (3) mengembangkan flasma nutfah pertanian untuk mendukung program penghijauan di kampus. Sehingga green campus yang dilakukan di Universitas Sulawesi Barat dimulai dari penghijauan ruang terbuka baik area parker maupun area terbuka lain melalui penanaman pohon ketapang (Termenelia mantily) dan ki hujan (Samanea saman).

Penghijauan dianggap sebagai slaah satu usaha penataan lingkungan dengan mempergunakan tanaman sebagai materi pokok dalam upaya yang dapat menanggulangi degradasi dan kualitas lingkungan. Di mana lingkungan yang sehat dan baik adalah hak dan kewajiban seluruh lapisan masyarakat baik swasta maupun pemerintah untuk mewujudkan kota yang berwawasan lingkungan, asri, serasi dan lestari salah satunya dapat diwujudkan melalui penanaman pohon dengan tujuan untuk (1) meningkatkan lualitas lingkungan hidup, (2) meningkatkan kota yang asri, serasi dan lestari serta (3) melaksanakan pembangunan yang berwawasan lingkungan.

Secara ekologis, lingkungan yang baik adalah yang seimbang antara struktur buatan manusai dan struktur buatan manusia. Kelompok pohon atau tanaman, air dan binatang adalah bagian dari alam yang dapat memberikan keseimbangan lingkungan. Sedangkan manfaat secara klimatologis yang dapat ditimbulkan dengan adanya pohon yaitu dapat menurunkan suhu setempat, sehingga udara di sekitarnya menjadi sejuk dan nyaman. Sehingga, secara klimatologis kehadiran kelompok pohon-pohon pelindung sangat besar peranannnya (Hidayanti, 2016)

Selain Undang-undang Nomor 32 Tahun 2009, beberapa dasar hukum lain yang 
berkaitan dengan penghijauan adalah sebagai berikut: (1) Undang-undang Nomor 4 Tahun 1982 tentang Pengelolaan Lingkungan Hidup; (2) Peraturan daerah Nomor 9 tahun 1985 tentang retribusi khusus mengenai pertanaman; (3) Inmendagri Nomor 14 Tahun 1988 tentang Ruang Terbuka Hijau; (4) Perda Nomor 11 Tahun 1988 tentang Ketertiban Umum dalam Wilayah DKI Jakarta Khusus Bidang Pertanaman; (5) Keputusan Presiden Nomor 20 Tahun 1992 tentang Program Penghijauan Nasional; (6) Gerakan penghijauan sejuta pohon yang dicanangkan presiden RI tanggal 10 Januari 1993, di Taman Medan Merdeka.

Mengingat pentingnya kesadaran akan lingkungan, sehingga melalui hibah pengabdian ini, diharapkan menjadi langkah awal untuk menghijaukan lingkungan kampus Universitas Sulawesi Barat yang kami sebut sebagai green campus, di mana kami akan melakukan penanaman di sekitar areal kampus sebanyak 100 tanaman yang terdiri dari pohon tanaman ketapang (Termenila mantily), pohon tanaman ki hujan (Samanea saman) dan beberapa tanaman lain yang dalam pemberdayaannya akan melibatkan mahasiswa Pertanian dan Kehutanan Universitas Sulawesi Barat.

Permasalahan yang dihadapi secara sederhana dapat diuraikan: (1) Masih belum diterapkannnya program penghijauan kampus secara berkala di lingkungan Universitas Sulawesi Barat; (2) Masih rendahnya kesadaran para stakeholders kampus untuk mencintai lingkungan terutama dalam hal penghijauan, dibuktikan dengan masih kurangnya pohon yang yang bisa menghijaukan kampus[ (3) Masih belum adanya program penghijauan yang melibatkan akademisi dan mahasiswa secara bersama-sama untuk mencintai lingkungan kampus.

Solusi yang ditawarkan melalui pengabdian ini adalah: (1) Melibatkan mahasiswa pertanian dan kehutanan untuk menanam pohon jenis Ketapang Kencana (Termenelia mantily) dan Ki Hujan (Samanea saman); (2) Menumbuhkembangkan kesadaran civitas akademika Universitas Sulawesi Barat pentingnya penghijauan terutama di lingkungan kampus; (3) Mensosialisasikan program green campus kepada seluruh stakeholders Universitas Sulawesi Barat terutama bagi dosen dan mahasiswa.

Target yang ingin dicapai melalui kegiatan pengabdian green campus ini adalah menjadikan Unsulbar sebagai cikal bakal kampus hijau yang sadar akan lingkungan yang diharapkan program ini bisa berkelanjutan melalui kesadaran menghijaukan lingkungan yang berawal dari lingkungan kampus kemudian memberikan multi effect kepada lingkungan sekitar untuk turut menghijaukan lingkungan Sulawesi Barat secara umum.

\section{METODE}

Kegiatan green campus dilaksanakan pada bulan Juli hingga Oktober 2018. Program green campus dilaksanakan di kampus Universitas Sulawesi Barat tepatnya di kampus Padang-padang, rektorat dan LPPM.

Alat dan bahan yang digunakan yaitu bibit tanaman ketapang kencana dan ki hujan, sekop, patok, karung, tali rapiah dan pupuk kandang/organik.

Kegiatan pelaksanaan Program green campus dikerjakan dengan metode sosialisasi kepada mahasiswa tentang pentingnya mencintai lingkungan dan melibatkan dalam penanaman pohon. Adapun tahapan pelaksanaan program green campus adalah sebagai berikut:

\section{HASIL DAN PEMBAHASAN}

Program green campus melalui penanaman pohon Ketapang Kencana (Termenelia matily) dan Ki Hujan (Samanea saman) di Universitas Sulawesi Barat telah dilaksanakan dengan melibatkan mahasiswa Fakultas Pertanian dan Kehutanan, Universitas Sulawesi Barat yakni Program Studi Agribisnis dan Kehutanan. Kegiatan penamanan pohon dilaksanakan di Universitas Sulawesi Barat tepatnya di sekitar area kampus yakni kampus Padang-Padang, rektorat Unsulbar dan LPPM. Penamanan dilakukan secara serentak selama 2-3 hari dengan titik-titik yang telah ditentukan. Jumlah tanaman yang ditanam sebanyak kurang lebih 100 pohon. Selain ketapang kencana dan ki hujan, juga terdapat tanaman lain seperti mahoni dan palem. 
Tahapan pelaksanaan Program Green Campus yang telah berjalan dapat diuraikan seperti berikut ini:

\section{Sosialisasi Program}

Sebuah pembangunan yang berdimensi lingkungan merupakan konsep pembangunan berkelanjutan yang telah disepakati oleh sebagian negara di dunia termasuk Indonesia. Pembangunan berwawasan lingkungan merupakan konsep, strategi dan model yang diharapkan mampu menjaga pelestarian fungsi lingkungan (Hadi, S, 2005). Green campus merupakan sistem pendidikan, penelitian dan pengabdian yang ramah lingkungan dengan melibatkan warga kampus sehingga dapat memberikan kontribusi positif bagi lingkungan, ekonomi dan sosial (Hapsari,I, Sumardjiyanto, \& Purwanti, 2014). Mahasiswa sebagai bagian dari insan akademik perlu dibekali dengan tanggung jawab secara moral dan sosial terhadap kesadaran dalam menjaga dan melestarikan lingkungan. Oleh karena itu, dalam program pengabdian ini, selain melibatkan dosen, juga dianggap perlu untuk melibatkan mahasiswa dalam proses penanaman pohon di sekitar areal kampus Universitas Sulawesi Barat. Seperti yang telah dilakukan oleh kampus UMY, dimana program green campus melibatkan mahasiswa secara langsung. Beberapa program yang dilaksanakan seperti pelatihan dan implementasi terkait pengelolaan sampah organik, penanaman tanaman produktif serta penghijauan areal kampus yang pelaksanaannya digelar dalam bentuk lomba

Sosialisasi program green campus kepada dilakukan melalui pertemuan informal dengan mengundang mahasiswa dari program studi agribinis dan kehutanan, fakultas pertanian dan kehutanan Universitas Sulawesi Barat . Melalui sosialisasi tersebut, disampaikan bahwa program terkait penghijauan dengan penanaman berbagai jenis tanaman, utamanya ketapang kencana (Termenelia katappa) dan Ki Hujan (Samanea zaman) juga beberapa tanaman sejenis akan dilakukan di sekitar kampus Universitas Sulawesi Barat. Selain itu pula, sosialisasi yang telah dilaksanakan ini merupakan bentuk penyadaran terhadap lingkungan, juga disampaikan secara teknis pelaksanaan kegiatan dan waktu pelaksanaan. Sosialisasi dihadiri oleh 10 (sepuluh) orang mahasiswa dari kedua prodi tersebut. Kegiatan sosialisasi dipandu langsung oleh 2 (dua) dosen yang merupakan bagian dari penanggungjawab program ini.

\section{Persiapan Penanaman}

Sebanyak kurang lebih 100 tanaman yang terdiri dari ketapang kencana, ki hujan dan beberapa tanaman tambahan seperti mahoni dan palem yang disebar di lokasi areal kampus Padang-Padang, rektorat dan LPPM. Persiapan penanaman meliputi pengadaan bibit tanaman dan serta bahan dan alat yang dibutuhkan seperti sekop, patok, karung dan pupuk.

a. Bibit tanaman utama yaitu ketapang kencana (Termenelia mantaly) dan Ki Hujan (Samanea saman Ketapang Kencana (Termenelia mantily)

Ketapang kecana adalah sejenis tanaman peneduh berwujud pohon yang merupakan tanaman endemik yang berasal dari Madagaskar.

Ketapang kencana dipilih sebagai tanaman yang akan ditanam pada program green campus karena memiliki manfaat yang sangat baik bagi lingkungan seperti: (1) menyerap polusi; ketapang kencana mampu menyerap polusi yang ada di lingkungan sekitarnya. Polusi yang berupa partikel debu yang berasal dari pembakaran sampah, lahan, asap kendaraan bermotor dan mobil. Polusi begitu mudah dijumpai di lingkungan kampus sehingga tanaman ini memiliki fungsi yang baik untuk menangkal dan mengurangi polusi kampus, apalagi area kampus termasuk area yang masih belum hijau dengan suhu udara yang cukup panas, (2) meningkatkan konsentrasi; pohon ketapang memiliki daun yang rindang sehingga teduh di bawahnya memberikan suasana nyaman. Dalam melakukan aktifitas belajar dan mengajar, jika dilakukan di bawah pohin ketapang kencana, dapat membantu untuk meningkatkan konsentrasi. Tujuannya konsentrasi yaitu agar pelajaran yang ditransfer oleh dosen, dapat diserap dengan baik oleh mahasiswa. Konsentrasi ini tentunya perlu didukung oleh suasana nyaman dan teduh, sehingga pohon ketapang kencana sangat cocok berada di areal kampus dimana proses belajar menngajar berlangsung, (3) menyejukkan 
sekitar; udara yang panas dan beriklim tropis seperti Majene, terkadang cukup gerah untuk belajar pada siang hari. Tumbuhan seperti halnya pohon ketapang mampu menghasilkan oksigen $\left(0_{2}\right)$ yang selain dibutuhkan oleh manusia untuk pernafasan, juga mampu menciptakan kesejukan daerah sekitarnya, (4) peneduh dari sinar matahari; manfaat cahaya matahari pada pagi hari cukup baik untuk kesehatan kulit. Namun pada siang hari, sinar matahari mengandung UVA dan UVB yang dapat menyebabkan kanker kulit jika terpapar terlalu sering dan lama. Pohon ketapang kencana memiliki dahan yang banyak dan bercabang sehingga bisa menjadi pelindung dari sinar matahari secara langsung.

\section{Ki Hujan (Samanea saman)}

Ki Hujan (Samanea saman) atau biasa juga disebut trembesi. Tumbuhan ini populer sebagai tumbuhan peneduh yang pohonnya besar, tinggi, dengan tajuk yang sangat melebar. Tumbuhan ini berasal dari Amerika tropik yang merupakan tanaman dengan kategori fast growing species (cepat tumbuh besar) yang memiliki berbagai manfaat sebagai berikut:

1) Tumbuhan peneduh; ki hujan atau trembesi banyak ditanam di pinggir jalan, terutama jika panas maka tanaman ki hujan dengan ukurannya yang besar dan daunnya yang rindang menjadi pelindung dari matahari dan memberikan efek sejuk dan segar.

2) Menyerap karbondioksida; karbondioksida dalah senyawa beracun bagi tubuh jika dihirup secara berlebihan. Jumlah karbondioksida terus bertambah seiring bertambahnya asap dari ekndaraan bermotor. Oleh karena itu, ki hujan merupakan salah satu tanaman yang memiliki fungsi untuk menyerap karbondioksida di udara lebih banyak dan lebih dari pohon-pohon lainnya.

3) Kaya oksigen; setiap pohon mengeluarkan oksigen dari hasil fotosintesisnya. Manfaat oksigen bagi manusia adalah untuk bernafas. Ki hujan adalah tanaman yang mampu mengeluarkan banyak oksigen sehingga saat berada di sekitarnya, tubuh akan merasa lebih segar.

4) Menyerap air; saat musim hujan datang, salah satu dampaknya adalah banjir. Banjir dapat terjadi karena aliran sungai yang tidak lancar dan disebabkan oleh sampah yang berserakan. Pohon ki hujan akan sangat cepat menyerap air pada musim hujan sehingga dapat mengurangi banjir.

b. Sekop; alat digunakan untuk untuk mencacah atau meratakan tanah atau media tanam, selain itu, sekop digunakan untuk memindahkan tanah ke dalam lubang tanaman yang telah disiapkan.

c. Bambu/patok; patok dari bambu digunakan untuk melindungi bibit tanaman yang baru saja di tanam dari gangguan binatang dan gangguan lainnya yang dapat merusak pertumbuhan tanaman. Patok juga berfungsi sebagai penyangga tanaman yang masih mudaagar tidak gampang goyah jika terkena angin kencang.

d. Karung; karung dibutuhkan untuk menyimpan bibit tanaman dan juga pupuk yang akan dipakai dalam penanaman.

e. Tali rapiah; tali rapiah digunakan untuk mengikat patok penyangga bibit tanaman,

f. Pupuk organik; pupuk organik dimasukkan ke dalam lubang yang telah ditanami bibit, membantu agar bibit tanaman dapat tumbuh dengan cepat dan pertumbuhannya baik. Pupuk dapat membentuk akar dari sistem perakaran yang kuat pada awal pertumbuhan tanaman dengan penyediaan unsur hara yang penting pada awal pertumbuhan tanaman.

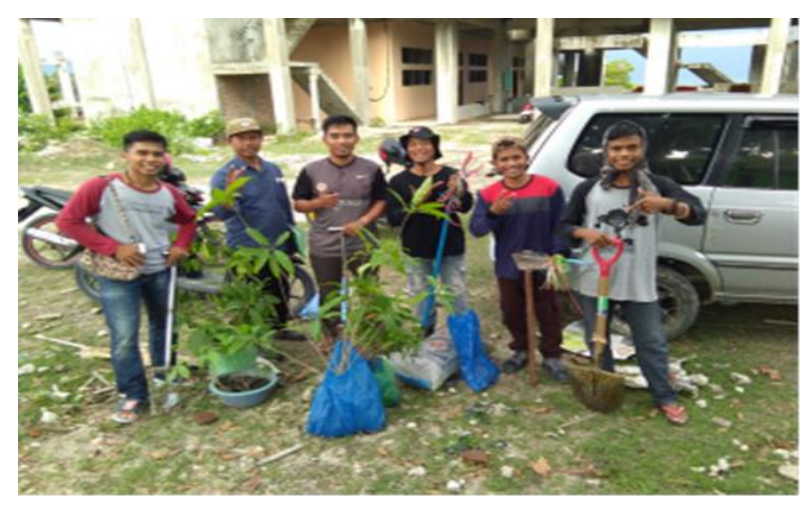

Gambar 1. Persiapan Penanaman

\section{Penentuan Titik Areal Penanaman}

Titik-titik penanaman yaitu di 3 (tiga) area utama yaitu kampus padang-padang, area perkantoran rektorat dan sekitar LPPM. 
Ketiga titik area ini sengaja dipilih dengan pertimbangan, jumlah pohon yang tumbuh di sekitarya masih kurang dan merupakan bangunan utama di Universitas Sulawesi Barat. Pada etiap titik-titk penanaman dibuat lubang, dimana lubang tanaman cukup menentukan tanaman dapat tumbuh dengan pertumbuhan yang baik dan kuat. Selain persiapan bibit yang baik, persiapan pembuatan lubang tanam sangat berpengaruh terhadap kualitas pertumbuhan tanaman. Pengaruhnya akan memberi efek dalam kurun waktu yang cukup panjang dan sangat mungkin dapat menyebabkan pertumbuhan tanaman tidak sesuai yang diharapkan seperti pertumbuhannya lambat, mal nutrisi, waktu tunggu tanaman dalam berproduksi menjadi lebih lama, tanaman rentan terhadap serangan hama dan penyakit. Oleh karean itu

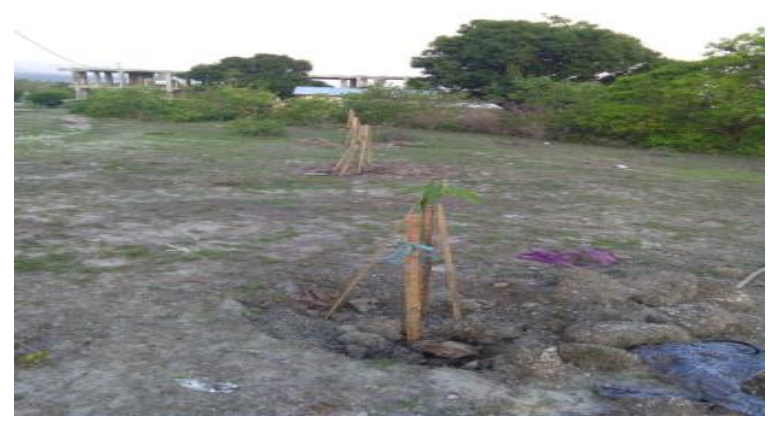

lubang tanaman harus dipersiapkan dengan baik, sebaik mempersiapkan bibit sebeum ditanam.

Gambar 2. Lokasi Penanaman Kampus Padang-Padang Unsulbar

Manajemen lubang tanam di mulai dengan memodifikasi ruang tumbuh akar pada awal pertumbuhan tanaman dengan menyediakan ruang tumbuh yang ideal, khususnya space untuk pertumbuhan akar. Pada setiap area yang akan ditanami, dibuat lubang dengan jarak antar lubang tanaman yaitu antara $3 \times 3,4 \times 4,5 \times 5$ meter tergantung kontur tanah dengan ukuran lubang yaitu 50 x 50 x $50 \mathrm{~cm}$. Lubang sengaja dibuat cukup besar, karena ukuran bibit tanaman cukup besar dan tinggi yaitu antara $0.5,1$ dan 1.5 meter, sehingga pada saat proses pertumbuhan, akar dapat tumbuh dengan baik dan kokoh. Dengan menyediakan ruang tumbuh yang ideal, akar tanaman dapat tumbuh secara optimal untuk mendukung pertumbuhan tanaman di atas tanah.
Manifestasi pertumbuhan tanaman yang baik terlihat dari pertumbuhan tanaman yang terlihat sehat dan kuat, sebaliknya kualitas pertumbuhan tanaman terlihat lambat dan jelek jika pertumbuhan akar di dalam tanah terhambat. Setelah semua tanaman telah ditanam, selanjutnya adalah melakukan perawatan secara berkala, yaitu dengan memberikan pupuk organik setiap 2-3 bulan sekali. Setelah titik areal ditentukan dan lubang yang telah dibuat, selanjutnya adalah menanam bibit tanaman. Bibit tanaman ditanam pada pagi hari. Pada lubang tanaman yang telah digali, bibit tanaman dimasukkan dalam lubang kemudian diberi pupuk organik/ kandang secara proporsional lalu ditimbun dengan tanah kemudian dipadatkan. Berikutnya tanaman yang telah ditanam dilakukan penyiraman agar media tanam lembab lalu dipasang patok penyangga.

\section{SIMPULAN DAN SARAN}

Simpulan dari pelaksanaan pengabdian program green campus adalah: (1) Stakeholder kampus dalam hal ini mahasiswa dan dosen terlibat langsung dalam program green campus melalui penanaman pohon ketapang kencana (Termenilia mantily) dan ki hujan (Samanea saman); (2) Program green campus telah terlaksana dengan baik yaitu penanaman lebih dari 100 bibit pohon ketapang kencana (Termenilia mantily) dan ki hujan (Samanea saman) dan bibit mahoni serta palem sebagai pelengkap di areal kampus yaitu di kampus utama Padang-padang, area perkantoran rektorat dan halaman sekitar LPPM.

Saran yang dapat diberikan adalah pembinaan dan pengelolaan green campus secara berkelanjutan sebagai wujud kesadaran dan kecintaan terhadap lingkungan dengan bekerja sama dengan pemerintah daerah setempat.

\section{DAFTAR RUJUKAN}

Alfianto, G. (2015). Upaya Reboisasi dan Penghijauan untuk Kesejahteraan Masyarakat.

Boer, R. (2014). Developing Innovative MRV System to Support the Realization of Eco/Green Campus IPB. Bogor. 
Makmur, Karim. Program Green kampus

Hadi, S, P. (2005). Dimensi Lingkungan

Perencanaan Pembangunan. Jogjakarta:

Cetakan Kedua; Gajah Mada University

Press.

Hapsari,I, D., Sumardjiyanto, N., \&

Purwanti, E. . (2014). Perencanaan dan

Penganggaran Green Campus

Universitas Diponegoro. Magister Ilmu

Ekonomi Dan Studi Pembangunan,

Universitas Diponegoro, 35(2). Retrieved

from

http://ejournal.undip.ac.id/index/php/ teknik.

Hidayanti, A. (2016). Lingkungan.

Nugraha, \& Adrian, R. (2015). Stop Pemanasan Global. Bekasi: Cahaya Pustaka Raga.

Www.umy.ac.id. (2017). No. Retrieved from http://www.umy.ac.id/program-greencampus-2017-langsung-libatkanmahasiswa.html 